\title{
RESPON PERTUMBUHAN BIBIT API-API ( Avicennia marina ) TERHADAP CEKAMAN MERKURI (Hg)
}

(Growth Response of Api-api (Avicennia marina )seeds towards mercury stress)

\author{
Muhammad Hafiz, Rosa Suryantini, Sarma Siahaan, Herlina Darwati \\ Fakultas Kehutanan Universitas Tanjungpura Jl. Daya Nasional, Pontianak 78124 \\ E-mail: Muhammadhafiz010794@gmail.com
}

\begin{abstract}
Api-api (Avicennia marina) has potential as the phytoremediation because it can live in a polluted environment. Api-api can be used as biological indicators of the environment that was polluted by heavy metals. The purpose of this research was to measure the effect of growth (the increase in diameter and the number of leaves) of api-api seeds on mercury stress with a dose of $0.5 \mathrm{ml}, 2 \mathrm{ml}$, and $3.5 \mathrm{ml}$. The research used an experimental method with a completely randomized design, which consists of 4 treatments and 5 repetitions. Each repetition consists of 1 plant, thus the number of seeds that have been observed was 20 plants. The results of the research showed that the mercury solution inhibited the increase in diameter and number of leaves with a confidence level of $95 \%$.
\end{abstract}

Keyword: Avicennia marina, mercury grip, seedling growth.

\section{PENDAHULUAN}

Hutan mangrove adalah suatu komunitas tumbuhan atau suatu individu jenis tumbuhan yang membentuk suatu komunitas di daerah pasang surut. Hutan mangrove disebut juga hutan bakau merupakan sebagian wilayah ekosistem pantai yang mempunyai karakteristik unik dan khas dan mempunyai potensi kekayaan hayati (Saparinto, 2007). Salah satu lokasi ekosistem tipe pantai mangrove di Provinsi Kalimantan Barat adalah hutan mangrove di Dusun Pasir Laut Desa Pasir Kecamatan Mempawah Hilir Kabupaten Mempawah.

Luas hutan Mangrove di kawasan tersebut kurang lebih seluas $4 \mathrm{Ha}$. Jenis tanah pada hutan mangrove di Mempawah Hilir adalah alluvial dan jenis tanah berlumpur (glei humus). Salah satu pencemaran logam berat yang menjadi masalah di Kabupaten Mempawah saat ini pencemaran merkuri. Kegiatan Emas Tanpa Izin (PETI) di sinyalir sebagai sumber pencemaran merkuri tersebut (Adijaya \& Yamashita 2004). Sementara itu Yulistiana (2007) menyatakan konsentrasi merkuri di sungai Kapuas yang melewati kota Pontianak berkisar antara 0,20-56,83 $\mu \mathrm{g} \mathrm{L}^{-1}$. Pada tahun 2011 di Muara Kapuas Kabupaten Kubu Raya yang menunjukan adanya kandungan merkuri pada sedimen dan TSS sebesar masing-masing 0,06-0,15 mg/L dan 1-3,5 $\mathrm{mg} / \mathrm{L}$ (Arifin dan Ilham, 2013). Konsetrasi merkuri tersebut telah melewati ambang batas yang diperbolehkan berdasarkan PP 82 tahun 2001 tentang Pengelolaan Kualitas Air dan Pengendalian Pencemaran Air. Dalam peraturan tersebut dinyatakan bahwa 
kriteria mutu air kelas I untuk parameter kimia $\mathrm{Hg}$ sebesar 0,001 $\mathrm{mg} / \mathrm{L}$ atau $1 \mu \mathrm{g} / \mathrm{L}$.

Menurut Amir Sumarto Rumalean (2019) Tegakan mangrove di wilayah tersebut didominasi oleh vegetasi jenis apiapi (Avicenia sp). Api-api merupakan salah satu jenis mangrove yang banyak di temui di daerah pesisir (Halidah, 2014).

Mangrove jenis Avicennia marina, Rhizophora mucronata, dan Bruguiera gymnorrhiza dapat menyerap logam berat dengan efektif. Namun api-api diperkirakan memiliki ketahanan yang lebih tinggi terhadap beberapa kandungan logam dibanding spesies mangrove yang lain (MacFarlane, et al, 2007).

Hal ini menjadi alasan utama bagi peneliti untuk mengetahui bagaimana pengaruh pertumbuhan (pertambahan diameter dan jumlah daun) bibit api-api pada cekaman merkuri dengan dosis 0,5 $\mathrm{ml}, 2 \mathrm{ml}$ dan 3,5 $\mathrm{ml}$. Tujuan penelitian ini untuk mengukur pengaruh pertumbuhan (pertambahan diameter dan jumlah daun) bibit api-api pada cekaman merkuri dengan dosis $0,5 \mathrm{ml}, 2 \mathrm{ml}$ dan $3,5 \mathrm{ml}$.

\section{METODE PENELITIAN}

Penelitian ini dilaksanakan pada bulan Oktober 2018 hingga Januari 2019 di Fakultas Kehutanan Universitas Tanjungpura. Bibit (umur 4 bulan) dan media tanam (lumpur) diambil di lokasi pembibitan Mempawah Mangrove Park.

Bahan yang diperlukan dalam penelitian ini
a. Tanaman api-api.
b. Lumpur.
c. Merkuri.
d. Aquades.

\section{Tahapan Penelitian}

Penyediaan media tanam

Media atau substrat yang digunakan pada penelitian ini yaitu lumpur yang di ambil dari muara kecil di Mempawah Mangrove Park. Media di ambil menggunakan cangkul, kemudian di simpan di dalam karung yang telah di siapkan. Lumpur yang telah di ambil, di masukkan ke dalam polybag sebanyak 2 $\mathrm{kg} /$ polybag $(10 \mathrm{x} 15 \mathrm{~cm})$.

Penanaman

Bibit yang di peroleh di tanam ke dalam polybag. Lakukan penyiraman pada pagi dan sore hari pada bibit sampai satu bulan. Setelah satu bulan, pilih bibit yang memiliki tinggi yang kurang lebih sama untuk diberi perlakuan

Pemberian perlakuan pada tanaman

Pemberian perlakuan dilakukan dengan cara memasukkan larutan Merkuri (Hg) ke dalam media tanam (lumpur) di sekitar perakaran bibit (1-1,5 cm dari batang utama) menggunakan jarum suntik. Adapun perlakuan yang dilakukan sebagai berikut:

A0 = Aquades (kosentrasi $\mathrm{Hg}=0 \mathrm{ml}$ )

$\mathrm{A} 1=0,5 \mathrm{ml}$ larutan merkuri $(\mathrm{Hg})$ (kosentrasi $\mathrm{Hg}=0,5 \mathrm{mg}$ )

$\mathrm{A} 2=2 \mathrm{ml}$ larutan merkuri $(\mathrm{Hg})$ (konsentrasi $\mathrm{Hg}=2 \mathrm{mg}$ )

$\mathrm{A} 3=3,5 \mathrm{ml}$ larutan merkuri $(\mathrm{Hg})$

(konsentrasi $\mathrm{Hg}=3,5 \mathrm{mg}$ )

Pemeliharan

Penyiraman dilakukan pada sore hari (16.00 WIB) dengan aquades serta dilakukan penyiangan jika diperlukan.

\section{Pengamatan dan Pengambilan Data}

Pengamatan dilakukan seminggu sekali selama 1 bulan. Adapun data yang diamati meliputi : 
Pertambahan Diameter

Menghitung pertambahan diameter dilakukan pada bagian pangkal batang yang telah di beri tanda menggunakan spidol, pengukuran diameter bibit ini menggunakan jangka sorong (alat pengukur diameter). Pengukuran pertambahan diameter dilakukan dari awal penelitian hingga akhir penelitian dengan cara menghitung selisih antara pengukuran awal dan pengukuran akhir.

Jumlah helai daun

Menghitung jumlah helai daun api-api pada setiap perlakuan. Perhitungan dilakukan dari awal penelitian sampai akhir penelitian.

\section{Rancangan Percobaan dan Analisis Data}

Penelitian ini menggunakan metode eksperimen dengan Rancangan Acak Lengkap (Completely Randomized
Design), yang terdiri dari 4 perlakuan dan 5 ulangan. Kemudian untuk membandingkan angka rerata perlakuan dan menentukan perlakuan mana yang nyata atau sangat nyata, dapat digunakan pengujian lanjut dengan Uji Beda Nyata Jujur (BNJ) dengan rumus sebagai berikut: $\mathbf{B N J}=\mathbf{Q}$ (p.n) $-\mathbf{S} \overline{\mathrm{X}}$

$\mathrm{Q} \quad=$ nilai pada tabel $\mathrm{Q}$ untuk tingkat $1 \%$

$\mathrm{P} \quad=$ banyaknya perlakuan

$\mathrm{N}=$ derajat bebas acak (error)

$\mathrm{S} \overline{\mathrm{X}}=$ hasil penarikan akar kuadrat tengah galat di bagi banyaknya ulangan $(\sqrt{ } \mathrm{KTG} / \mathrm{r})$.

\section{HASIL PENELITIAN}

\section{Pertambahan Diameter Bibit}

Data pengamatan merkuri berpengaruh terhadap diameter bibit apiapi dapat dilihat pada Tabel 1 .

Tabel 1. Analisis Keragaman Pengaruh Merkuri Terhadap Pertambahan Diameter Bibit Api-api (Analysis of diversity of the influence of mercury on increase in the diameter of the api-api).

\begin{tabular}{lcccccc}
\hline \multicolumn{1}{c}{ Sumber } & Derajat & Jumlah & Kwadrat & \multirow{2}{*}{ F Hitung } & \multicolumn{2}{c}{ F Tabel } \\
Keragaman & Bebas & Kuadrat & Tengah & 2 & $1 \%$ \\
\hline Perlakuan & 3 & 0,492 & 0,164 & $4,315789 *$ & 3,24 & 5,29 \\
Galat & 16 & 0,608 & 0,308 & & & \\
\hline Total & 19 & 1,1 & & & & \\
\hline
\end{tabular}

Keterangan : * = Berbeda nyata pada tingkat kepercayaan $95 \%$

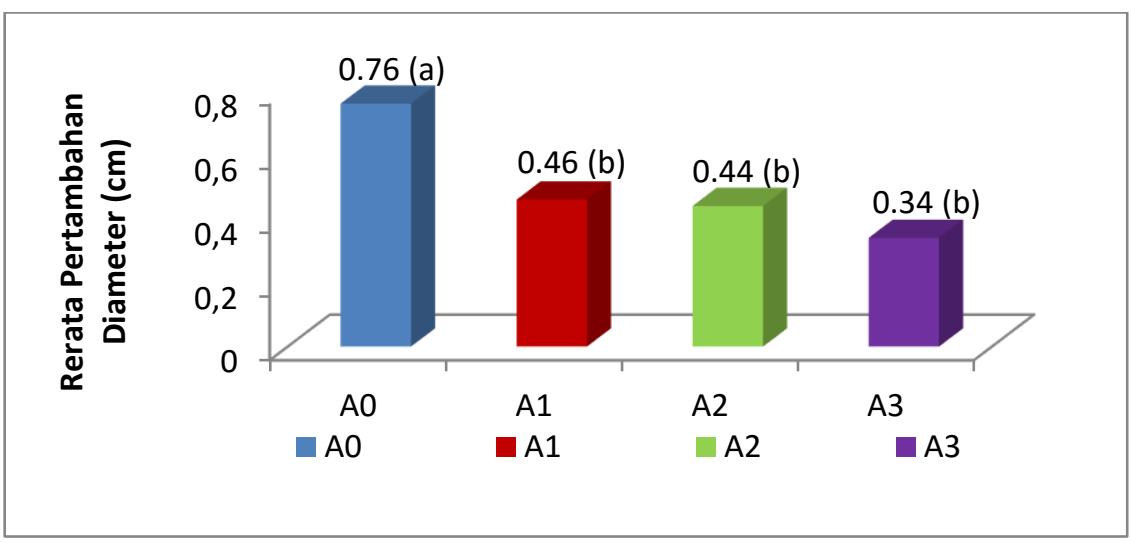


Gambar 1. Rerata Pertambahan Diameter Bibit Api-api (average increase in diameter of the api-api seeds).

Gambar 1 menjelaskan bahwa rerata pertambahan diameter bibit apiapi pada kontrol berbeda nyata dengan rerata pertambahan diameter bibit apiapi yang di beri perlakuan. Pada penelitian Edi Mulyadi (2009) menjelaskan bahwa tanaman api-api dapat mengakumulasi logam berat. Selain akumulasi, api-api memiliki upaya penanggulangan toksik dalam jaringan tubi (Kontrol) $(0,5 \mathrm{ml}) \quad(2 \mathrm{ml})$ toksisitas logam tersebut. Menurut Darmono (1995) dalam Edy Mulyadi (2009) metabolisme atau transformasi secara biologis (biotransformasi) logam berat yang masuk kedalam tubuh tanaman akan mengalami pengikatan dan penurunan daya racun, karena diolah menjadi bentuk-bentuk persenyawaan yang lebih sederhana.
Perbedaan diameter batang pohon menentukan banyaknya logam berat dan zat-zat lain yang terakumulasi di dalam pohon tersebut (Agriani, 2016). Merkuri mempunyai efek yang sangat toksik pada konsentrasi tertentu sehingga bisa memperhambar suatu proses pertumbuhan (Muhammad Shofi, 2017).

Penelitian ini selaras dengan penelitian Miftahul Mawaddah (2012)

$(3,5 \mathrm{ml})$ ıskan bahwa pertambahan diameter pada tanaman kayu putih (Melaleuca leucadendron Linn.) dan longkida (Nauclea orientalis Linn.) berpengaruh nyata pada kondisi tergenang air asam tambang.

\section{Pertambahan Daun Bibit}

Data pengamatan merkuri berpengaruh terhadap pertambahan daun bibit dapat dilihat pada Tabel 2 .

Tabel 2. Analisis Keragaman Pengaruh Merkuri Terhadap Pertambahan Daun Bibit Api-api (Analysis of diversity of the influence of mercury on increase in the leaves of the api-api).

\begin{tabular}{lcccccc}
\hline \multicolumn{1}{c}{$\begin{array}{c}\text { Sumber } \\
\text { Keragaman }\end{array}$} & Derajat & Jumlah & Kwadrat & \multirow{2}{*}{ F Hitung } & \multicolumn{2}{c}{ F Tabel } \\
Perlakuan & 3 & 11,8 & 3,9333 & $7,8667 * *$ & 3,24 & 5,29 \\
Galat & 16 & 8 & 0,5 & & & \\
\hline Total & 19 & 19,8 & & & & \\
\hline
\end{tabular}

Keterangan : $* *$ = Sangat nyata pada tingkat kepercayaan $99 \%$

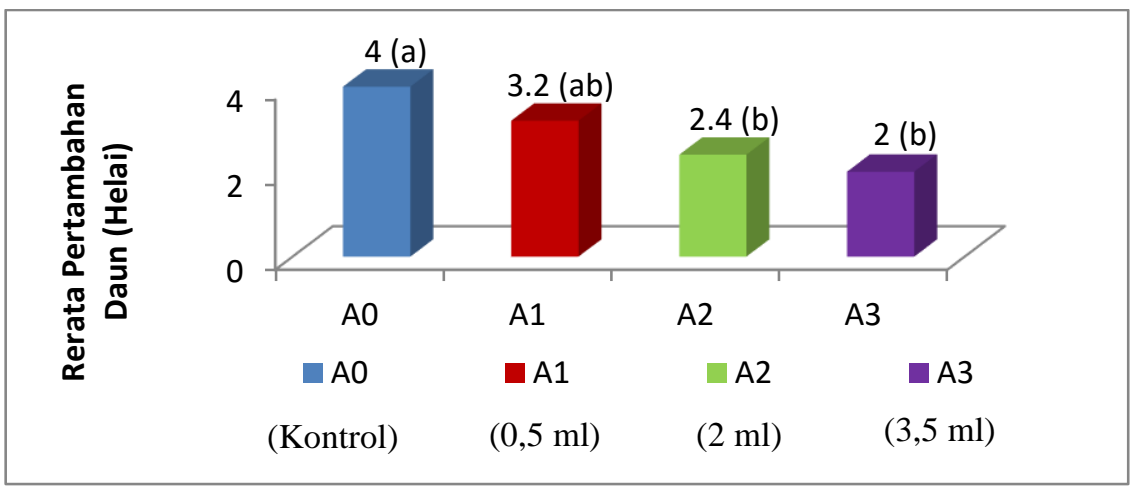


Gambar 2. Rerata Pertambahan Daun Bibit Api-api (average increase in the leaves of the api-api seeds).

Gambar 2 menjelaskan bahwa rerata pertambahan jumlah daun bibit api-api pada kontrol berbeda nyata dengan rerata pertambahan jumlah daun bibit api-api yang di beri perlakuan. Menurut Kamaruzzaman (2008) dalam Heru Setiawan (2013) menjelaskan bahwa mangrove memiliki kemampuan menyerap bahan-bahan organik dan non-organik dari lingkungannya kedalam tubuh melalui membran sel. Walaupun banyak masukan sumber bahan pencemar, mangrove memiliki toleransi yang tinggi terhadap logam berat. Menurut Hamzah dan Setiawan (2010) menyatakan bahwa mangrove jenis api-api mempunyai kemampuan mengakumulasi logam berat lebih tinggi di bandingkan dengan jenis mangrove lainnya. Hal ini di sebabkan oleh letak atau posisi tempat tumbuh api-api yang berada pada zona terdepan. Menurut Tangahu (2011) dalam Titi Wulandari (2018) menjelaskan penyerapan dan akumulasi logam berat oleh mangrove dapat dibagi menjadi tiga proses berkesinambungan, yaitu penyerapan logam oleh akar, translokasi logam dari akar ke bagian tumbuhan yang lain dan lokalisasi logam pada bagian sel tertentu. Menurut Taiz dan Zeiger (2010), secara umum cengkaman logam berat menyebabkan kerusakan intraseluler dan ekstraseluler yang mengakibatkan gangguan pertumbuhan.

Hasil pada penelitian ini selaras dengan penelitian Munawar Ali dan Rina (2010) menjelaskan bahwa jika pembentukan klorofil terganggu, maka proses fotosistesis juga akan terganggu, pada akhirnya akan mengganggu pertumbuhan yang mengakibatkan rusaknya sel-sel pada daun hingga menyebabkan matinya suatu tanaman. Hal ini sangat bertolak belakan pada kontrol tanaman tumbuh dengan normal.

\section{KESIMPULAN}

Tanaman api-api merupakan salah satu tanaman mangrove yang mampu hidup pada lingkungan yang tercemar, berdasarkan hasil penelitian tanaman api-api masih mampu bertahan hidup pada konsentrasi $\mathrm{Hg}$ 3,5 $\mathrm{ml}$, namun mengalami perlambatan pertumbuhan dibandingkan dengan tanaman api-api yang di tanam pada konsentrasi $\mathrm{Hg} 0 \mathrm{ml}$ (kontrol).

\section{DAFTAR PUSTAKA}

Adijaya M, Yamashita T. 2004. Mercury Pollutant in Kapuas River Basin : Current Status and Strategic Approaches. Annuals of Disas. Prev. Res. Inst., Kyoto Univ. No. 47 B.

Arifin Z \& Azis Ismail M. F. 2013. Dinamika Temporal Kandungan Merkuri Terlarut, Terendapkan dan Tersuspensi di Perairan Estuari Kapuas Kecil Kalimantan Barat. No. 1 : 37-44.

Boucher Marie. 2007. From Primary to Secondary Growth: Origin and Development of The Vascular System. Journal of Experimental Botany. 58 (13) : 3485-3501. 
Halidah. 2014. Avicennia marina (Fossk). Vierh Jenis Mangrove yang Kaya Manfaat. Info Teknis Eboni. Vol 11 (1) : 37-44.

Hamzah F \& Setiawan A. 2010.Akumulasi Logam Berat Pb, $\mathrm{Cu}$ dan $\mathrm{Zn}$ di Hutan Mangrove Muara Angke, Jakarta Utara. Jurnal Ilmu dan Teknologi Kelautan Tropis. Vol. 2 (2) : 4152.

MacFarlane, G.R., Pulkownik, and Burchett, M.D. 2007. Acumulation And Distribution of Heavy Metal In The Grey Mangrove, Avicennia marina (Forsk) Vierh : Biological Indication Potential. Environmental Pollution. Vol. 123 :139-151.

Mawaddah M. 2012. Pertumbuhan Kayu Putih (Melaleuca leucadendron Linn.) dan Longkida (Nauclea orientalis Linn.) pada Kondisi Tergenang Air Asam Tambang. Jurnal Silvikultur Tropika. Vol. 03(2) : 71-75.

Mulyadi E. 2009. Fungsi Mangrove Sebagai Pengendali Pencemar Logam Berat. Jurnal Ilmiah Teknik Lingkungan. Vol. 1 : 3340.

Munawar Ali \& Rina. 2010. Kemampuan Tanaman Mangrove untuk Menyerap Logam Berat Merkuri $(\mathrm{Hg})$ dan Timbal $(\mathrm{Pb})$. Envirotek. Jurnal Ilmiah Teknik Lingkungan. Vol. 2 (2) : 28-36.

Setiawan H. 2013. Akumulasi dan Distribusi Logam Berat Pada Vegetasi Mangrove di Perairan Pesisir Sulawesi Selatan. Jurnal
Ilmu Kehutanan. Vol. 7 (1) : 1224.

Shofi M. 2017. Pengaruh Logam Berat Merkuri (Hg) Terhadap Perkecambahan Biji Kacang Hijau (Vigna radiata L.).Jurnal Wiyata. Vol. 4 (1) : 84-89.

Suharto Rumalean, A. 2019. Struktur Komunitas Hutan Mangrove Pada Kawasan Mempawah Mangrove Park di Desa Pasir Mempawah Hilir. Jurnal Ilmu dan Teknologi Kelautan Tropis. Vol. 11 (1) : 221-230.

Wulandari T. 2018. Kemampuan Akumulasi Timbal (Pb) Pada Akar Mangrove Jenis Avicennia marina (Forsk.) dan Rhizophora mucronata (Lamk.) di Lahan Tambak Mangunharjo Semarang. Jurnal Biologi. Vol. 7 (1) : 89-96.

Yulistiana L. 2007. Penentuan Kualitas Air dan Kajian Daya Tampung Sungai Kapuas, Kota Pontianak. Tesis. Institut Pertanian Bogor. 